\title{
Relating tropical ocean clouds to moist processes using water vapor isotope measurements
}

\author{
J. Lee ${ }^{1}$, J. Worden ${ }^{1}$, D. Noone ${ }^{2}$, K. Bowman ${ }^{1}$, A. Eldering ${ }^{1}$, A. LeGrande ${ }^{3}$, J.-L. F. Li ${ }^{3}$, G. Schmidt ${ }^{3}$, and \\ H. Sodemann ${ }^{4}$ \\ ${ }^{1}$ Jet Propulsion Laboratory, California Institute of Technology, Pasadena, California, USA \\ ${ }^{2}$ Department of Atmospheric and Oceanic Sciences and Cooperative Institute for Research in Environmental Sciences, \\ University of Colorado, Boulder, Colorado, USA \\ ${ }^{3}$ NASA Goddard Institute for Space Studies and Center for Climate Systems Research, Columbia University, New York, \\ New York, USA \\ ${ }^{4}$ Norwegian Institute for Air Research (NILU), Kjeller, Norway
}

Received: 1 June 2010 - Published in Atmos. Chem. Phys. Discuss.: 20 July 2010

Revised: 13 January 2011 - Accepted: 18 January 2011 - Published: 26 January 2011

\begin{abstract}
We examine the co-variations of tropospheric water vapor, its isotopic composition and cloud types and relate these distributions to tropospheric mixing and distillation models using satellite observations from the Aura Tropospheric Emission Spectrometer (TES) over the summertime tropical ocean. Interpretation of these process distributions must take into account the sensitivity of the TES isotope and water vapor measurements to variations in cloud, water, and temperature amount. Consequently, comparisons are made between cloud-types based on the International Satellite Cloud Climatology Project (ISSCP) classification; these are clear sky, non-precipitating (e.g., cumulus), boundary layer (e.g., stratocumulus), and precipitating clouds (e.g. regions of deep convection). In general, we find that the free tropospheric vapor over tropical oceans does not strictly follow a Rayleigh model in which air parcels become dry and isotopically depleted through condensation. Instead, mixing processes related to convection as well as subsidence, and reevaporation of rainfall associated with organized deep convection all play significant roles in controlling the water vapor distribution. The relative role of these moisture processes are examined for different tropical oceanic regions.
\end{abstract}

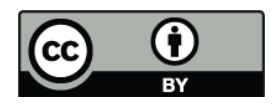

Correspondence to: J. Lee (jeonghoon.d.lee@gmail.com)

\section{Introduction}

Stable isotopic observations of water vapor and precipitation are useful in quantifying global or local distributions of exchange processes between vapor, ice and water clouds, and precipitation and characterizing sources of water because lighter isotopes preferentially evaporate and heavier isotopes preferentially condense, leading to an isotopic fingerprint of condensation history (e.g., Kuang et al., 2003; Dessler and Sherwood, 2003; Noone and Simmonds, 2004; Gettelman and Webster, 2005; Schmidt et al., 2005). Observations of the isotopic composition of precipitation, for example, GNIP database (IAEA/WMO, 2006), have been used not only to characterize moisture sources (Masson-Delmotte et al., 2005), but also to infer cloud processes (Ciais and Jouzel, 1994; Lawrence and Gedzelman, 1996; Gedzelman et al., 2003; Lee and Fung, 2007; Bony et al., 2008; Risi et al., 2008a). However, measuring the isotopic composition of water vapor can provide a more direct link to understanding cloud processes (e.g., Moyer et al., 1996; Webster and Heymsfield, 2003; Lawrence et al., 2004; Worden et al., 2007; Lee et al., 2009; Frankenberg et al., 2009) because of a shorter history between the phase changes related to the cloud and because the isotopic composition of precipitation can equilibrate to boundary layer values as it falls (e.g., Gat, 1996, 2000; Lee and Fung, 2007).

Isotope enabled general climate models (GCMs) are useful for understanding the global distribution of moisture processes affecting the distribution of water vapor and its isotopic composition. For example, Wright et al. (2009) used

Published by Copernicus Publications on behalf of the European Geosciences Union. 
an isotope enabled GCM to show that condensate evaporations play a role in humidifying the troposphere by comparing two model runs in which one of the runs disabled condensate evaporation. Lee et al. (2009) showed how water vapor isotope can be used as a constraint of convective parameterization in a GCM. In addition, Risi et al. (2008a) used a single column model to explain a short term, "amount effect", in which isotopically depleted rainfall in tropical convective regions is linked to reevaporation of the falling rain, diffusive exchanges with the surrounding vapor and the injection of vapor from the unsaturated downdraft into the subcloud layer.

Recently, satellite observations of tropospheric water vapor and its isotopic composition have become available (Herbin et al., 2007; Worden et al., 2007; Frankenberg et al., 2009). These new measurements have the potential to add insight characterizing the distribution of moist processes affecting the distribution of water vapor. However, difficulties remain in interpreting these data because the sensitivity of the isotopic measurements, depending on water vapor amount, temperature, and cloud optical properties (Worden et al., 2006). However, the isotopic composition of vapor also depends on these microphysical properties; consequently it can be challenging to relate isotopic measurements taken under different microphysical states.

In this paper, we investigate the capability of Aura Tropospheric Emission Spectrometer (TES) satellite measurements to provide insight into tropical moisture processes by examining co-variations of tropical clouds, water vapor and isotopic composition measurements from TES. We relate these distributions to tropospheric mixing and condensation models (e.g., Worden et al., 2007). We also examine how water vapor and its isotopic composition vary at different tropical locations that are affected differently by the large scale atmospheric processes such as organized convection and the Walker and Hadley circulations. Better characterization of the relationship between isotope and clouds allow the TES data to be more effectively used to compare with GCMs enabled with isotope physics (Noone and Simmonds, 2002; Schmidt et al., 2005; Lee et al., 2007; Yoshimura et al., 2008; Tindall et al., 2009).

\section{Methods}

\subsection{TES instrument}

The Tropospheric Emission Spectrometer (TES) on the EOSAura platform is a nadir viewing infrared Fourier transform spectrometer that covers a spectral range between $650 \mathrm{~cm}^{-1}$ and $3050 \mathrm{~cm}^{-1}$ (Beer, 2006). The footprint of each nadir observations is approximately $5.3 \mathrm{~km} \times 8.5 \mathrm{~km}$. In the nadir view, TES data have been sensitive to the abundant tropospheric gas species including $\mathrm{H}_{2} \mathrm{O}$ and HDO (Worden et al., 2006). The estimated HDO is primarily sensitive to emis- sion between $850 \mathrm{hPa}$ and $400 \mathrm{hPa}$ (Worden et al., 2006). As such, we restrict our analysis to lower troposphere or free troposphere $(850-500 \mathrm{hPa})$ mean values except in convective regions where significant water amounts increases the sensitivity of the TES data to HDO at higher altitudes. (Worden et al., 2007; Brown et al., 2008).

\subsection{Isotopic composition of water vapor $(\delta D)$}

We use TES v003 data (R10). TES data used in this work come from June 2005 to August 2008 over the tropical ocean (latitude between $-15^{\circ}$ and $15^{\circ} \mathrm{N}$ ) and one data set is generated from June to August (JJA) of each year. For the analysis shown here, we only use the data where the Degrees-ofFreedom for signal (DOF) for the HDO retrievals are larger than 0.5 (Worden et al., 2007; Brown et al., 2008) in all sky conditions. Note that only the HDO DOF's are used as a sensitivity metric because the sensitivity of the TES $\mathrm{H}_{2} \mathrm{O}$ estimate will always vertically overlap that of the HDO measurement sensitivity but not necessarily the reverse. In addition, as noted in Worden et al. (2006), the DOFs for the $\mathrm{HDO} / \mathrm{H}_{2} \mathrm{O}$ estimate is degenerate and therefore is not calculated. For example, the assumed variance in the a priori constraint is approximately $100 \%$ relative to Vienna Standard Mean Ocean Water (VSMOW). After the retrieval, the random uncertainty in a tropical $\mathrm{HDO} / \mathrm{H}_{2} \mathrm{O}$ column average is approximately $15 \%$ or less for retrievals with a DOF of 0.5 or higher (Worden et al., 2006).

The $\mathrm{HDO} / \mathrm{H}_{2} \mathrm{O}$ ratios were expressed in the $\delta$ notation as a part of thousand difference relative to VSMOW following by the definition

$\delta D=\left[\frac{\left(\mathrm{HDO} / \mathrm{H}_{2} \mathrm{O}\right)_{\mathrm{obs}}-\left(\mathrm{HDO} / \mathrm{H}_{2} \mathrm{O}\right)_{\text {VSMOW }}}{\left(\mathrm{HDO} / \mathrm{H}_{2} \mathrm{O}\right)_{\text {VSMOW }}}\right] \times 1000$

where $\mathrm{HDO}$ and $\mathrm{H}_{2} \mathrm{O}$ are proportional to the number of molecules of each species. The ratio $\left(\left(\mathrm{HDO} / \mathrm{H}_{2} \mathrm{O}\right)_{\text {VSMOW }}\right)$ is $311.52 \times 10^{-6}$ by volume.

There is a bias in the $\mathrm{HDO} / \mathrm{H}_{2} \mathrm{O}$ ratio of approximately $6 \%$ (Worden et al., 2006), assumed to be related to the spectroscopic line strengths of $\mathrm{HDO}$ or both $\mathrm{HDO}$ and $\mathrm{H}_{2} \mathrm{O}$ combined. This bias must be corrected for in order to better compare the TES isotope data to the moisture process models shown in this work. The bias correction must also account for the sensitivity of the measurement because altitude regions where there is little sensitivity will be more dependent on the a priori constraint vector used for the $\mathrm{HDO} / \mathrm{H}_{2} \mathrm{O}$ joint profile retrieval. Using comparisons to in situ measurements of $\mathrm{HDO}$ and $\mathrm{H}_{2} \mathrm{O}$ in Hawaii at different altitudes, the form of the correction should be:

$\ln \left(\boldsymbol{q}_{\text {corrected }}^{\mathrm{HDO}}\right)=\ln \left(\boldsymbol{q}_{\text {original }}^{\mathrm{HDO}}\right)-\boldsymbol{A}\left(\boldsymbol{\delta}_{\text {bias }}\right)$

where $\boldsymbol{q}_{\text {original }}^{\mathrm{HDO}}$ is the volume mixing ratio of the HDO profile as provided in the product files, $\mathbf{A}$ is the averaging kernel matrix (also provided in the product files), and $\boldsymbol{\delta}_{\text {bias }}$ is a column 
Table 1. The mean, standard deviation and standard error of the mean for TES water vapor measurements and $\mathrm{HDO} / \mathrm{H}_{2} \mathrm{O}$ ratio $($ in parts per mil relative to SMOW) for the June, July and August months between 2005 and 2008 over the tropical ocean. All mean $\delta D$ values are mass-weighted. Standard error of the mean is presented in parenthesis next to standard deviation. The frequency of observations from the ozone profile step, which is the TES retrieval that is most sensitive to all cloud types, is denoted as $f_{1}$. The distributions of cloud optical properties from the water vapor retrieval step are shown in the second column (denoted as $f_{2}$ ).

\begin{tabular}{|c|c|c|c|c|c|c|}
\hline & $f_{1}$ & $f_{2}$ & $\begin{array}{l}\mathrm{H}_{2} \mathrm{O}(\mathrm{g} / \mathrm{kg}) \\
{[850-500 \mathrm{hPa}]}\end{array}$ & $\begin{array}{l}\delta D(\% o) \\
{[850-500 \mathrm{hPa}]}\end{array}$ & $\mathrm{H}_{2} \mathrm{O}(\mathrm{g} / \mathrm{kg})$ & $\delta D(\% o)$ \\
\hline Clear sky & 59.9 & 64.5 & $4.6 \pm 1.9(0.02)$ & $\begin{array}{l}-164.3 \pm 22.1 \\
(0.11)\end{array}$ & & \\
\hline Nonprecipitating clouds & 34.3 & 33.3 & $5.8 \pm 1.8(0.04)$ & $\begin{array}{l}-167.8 \pm 21.7 \\
(0.16)\end{array}$ & & \\
\hline Boundary layer clouds & 2.9 & 2.0 & $4.8 \pm 1.8(0.14)$ & $\begin{array}{l}-184.3 \pm 20.2 \\
(0.59)\end{array}$ & $\begin{array}{l}2.4 \pm 1.1 \\
(0.07) \\
{[700-} \\
400 \mathrm{hPa}]\end{array}$ & $\begin{array}{l}-232.0 \pm 26.4(0.77) \\
{[700-400 \mathrm{hPa}]}\end{array}$ \\
\hline Precipitating clouds & 3.0 & 0.2 & $8.0 \pm 1.1(0.79)$ & $\begin{array}{l}-182.9 \pm 15.1 \\
(1.49)\end{array}$ & $\begin{array}{l}2.7 \pm 0.9 \\
(0.27) \\
{[600-} \\
300 \mathrm{hPa}]\end{array}$ & $\begin{array}{l}-266.1 \pm 18.1(1.79) \\
{[600-300 \mathrm{hPa}]}\end{array}$ \\
\hline
\end{tabular}

vector of the same length as $\boldsymbol{q}_{\text {original }}^{\mathrm{HDO}}$ that contains the values 0.06. Note that this correction is only applied to HDO and not to $\mathrm{H}_{2} \mathrm{O}$.

\subsection{TES cloud observations}

\subsubsection{TES cloud retrievals and characteristics}

We use TES v003 data of cloud optical depth (COD) and cloud top pressure (CTP) characterized and validated by $\mathrm{Ku}$ lawik et al. (2006) and Eldering et al. (2008). TES measures radiances in the infrared spectral region, where clouds have a ubiquitous impact and therefore affect on trace gas profile retrievals (Eldering et al., 2008). The radiance contribution of clouds is parameterized in terms of a set of frequencydependent non-scattering effective optical depths and a cloud height, retrieved jointly with surface temperature, emissivity, atmospheric temperature, and trace gases from spectral data (Kulawik et al., 2006). Eldering et al. (2008) shows that cloud top height errors range between 100 to $200 \mathrm{hPa}$, depending on the sensitivity of the measurement to cloud-top height. This sensitivity will vary strongly with the optical thickness of the cloud. For example, between COD of 0.1 to 0.5 , the uncertainty of the CTP is approximately $200 \mathrm{hPa}$ and the uncertainty in the effective cloud optical depth is about 0.1. For larger optical depths, the uncertainty in the CTP decreases to approximately $100 \mathrm{hPa}$ but the uncertainty in the effective (true) CTP can dramatically increase because distinguishing between large optical depths becomes limited by the signal-to-noise of the radiances (Eldering et al., 2008).

\subsubsection{Mapping TES cloud properties to ISCCP cloud properties}

The TES retrievals of CTP and COD are used to classify different cloud types according to the International Satellite Cloud Climatology Project (ISCCP) cloud types as proposed by Rossow and Schiffer (1999) (http://isccp.giss.nasa.gov). We sub-divide the ISCCP categories into more general categories of nonprecipitating clouds (COD greater than 0.2 and less than 3.6, e.g., cumulus and cirrus), boundary layer clouds (COD greater than 3.6 and CTP greater than $680 \mathrm{hPa}$, e.g. stratus and stratocumulus) and precipitating clouds associated with deep convection (COD greater than 3.6 and CTP less than $680 \mathrm{hPa}$ ), as well as clear sky (COD less than 0.2 ) (Liu et al., 2008). These definitions are chosen (1) in order to best match the TES measured cloud optical properties to the ISCCP cloud definitions and (2) because the sensitivity of the TES water isotope measurements varies with the optical properties of these different cloud types.

The distributions for these clouds are shown in Table 1. We use the cloud optical properties estimated from the TES ozone profile retrieval to obtain the best distribution of cloud optical properties because all cloud types in the troposphere will affect the ozone profile retrieval, which extends through the stratosphere (Kulawik et al., 2006; Eldering et al., 2008). These distributions from the ozone profile step are shown in the first column of Table 1 (denoted as $f_{1}$ ). Table 1 shows that clear sky data is approximately $60 \%$ of all sky, and nonprecipitating, boundary layer and precipitating clouds are approximately $34 \%, 3 \%$, and $3 \%$ of all sky, respectively. However, convective clouds cannot be well estimated during the water vapor isotope retrievals because the cloud top pressure is at altitudes where the TES water vapor retrievals show little 

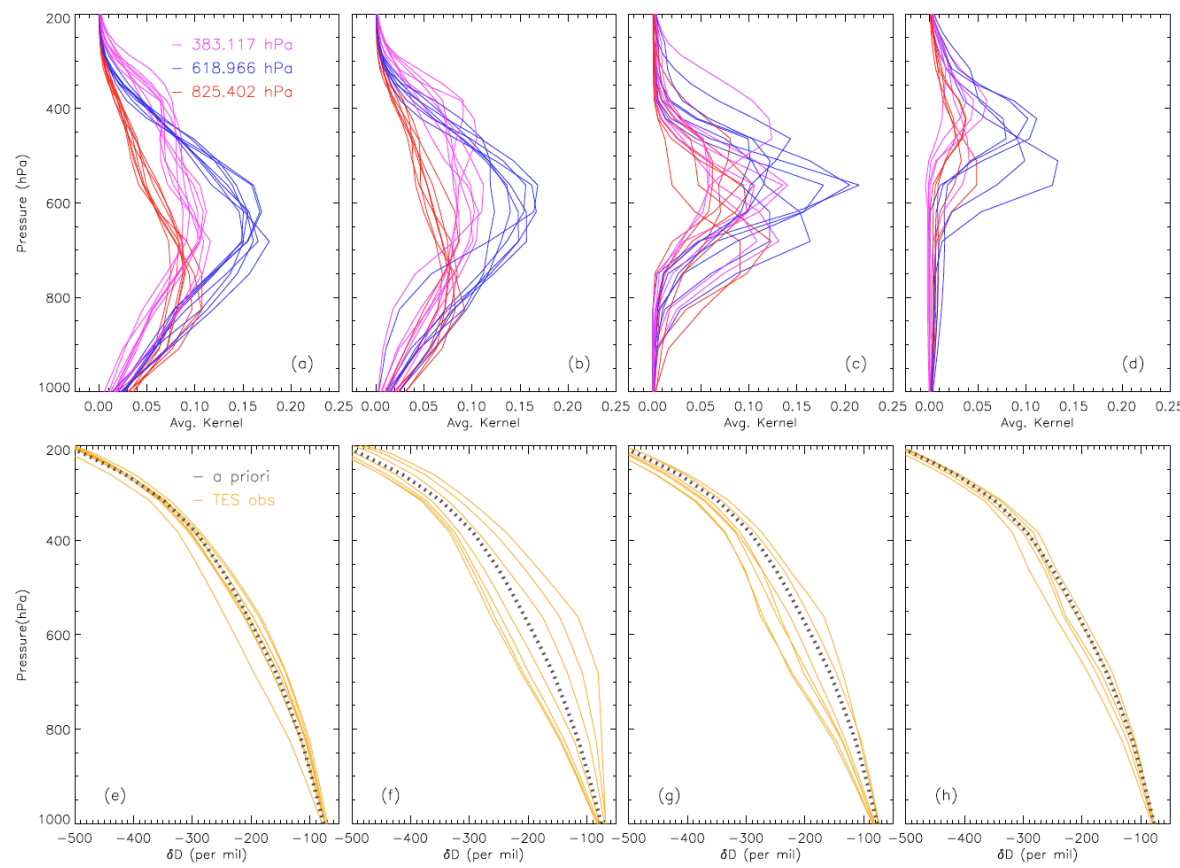

Fig. 1. TES averaging kernel rows corresponding to 825,619 and $383 \mathrm{hPa}$ and the a priori and the retrieved TES $\delta D$ profile. Selected TES observations are over tropical ocean during 1 August 2007 (Run ID, 5889) except precipitating clouds (Three global measurements are selected due to lack of sampling number). (a) and (e) Clear sky, (b) and (f) nonprecipitating clouds, (c) and (g) boundary layer clouds and (d) and (h) precipitating clouds from 1 August 2007 to 8 August 2007 (Run ID, 5889, 5918 and 5948).

sensitivity. The distributions of cloud optical properties from the water vapor retrieval step are shown in the second column of Table 1 (denoted as $f_{2}$ ). These differences in the distributions must be accounted for when understanding the impact of the different clouds on the total distribution for water vapor isotopes versus what is measured by TES. For example, a significant difference is that only $0.3 \%$ of the data show sensitivity around tropical convective/precipitating clouds but these clouds actually make up nearly $3 \%$ of the distribution as seen in the first column of Table 1. These differences are used to help interpret the data in Section 3 and also critical when comparing satellite data with model data. For example, the distribution of these clouds observed by TES will likely be different than that observed in a model. Consequently, all-sky TES data will have a different weighting of cloud distributions versus all-sky model data; these differences must be accounted when comparing isotope composition for these different cloud types (Su et al., 2009).

\subsubsection{Sensitivity of $\mathrm{HDO} / \mathrm{H}_{2} \mathrm{O}$ profiles for different cloud regimes}

Estimated TES HDO profiles depend on cloud optical properties, such as cloud optical depth and cloud top height. Figure 1 is an example illustrating the relationship between TES sensitivity and clouds types. Figure 1a-d show examples of the rows of TES averaging kernels corresponding to 825, 619 and $383 \mathrm{hPa}$. Figure 1e-h show the a priori (dotted blue) constraint and retrieved estimates. As shown in Fig. 1a and 1b, the TES estimates for clear sky and non-precipitating clouds are primarily sensitive to the altitude regions 850 and $500 \mathrm{hPa}$ with peak sensitivity at approximately $675 \mathrm{hPa}$. For boundary layer clouds (e.g. stratocumulus), the sensitivity to HDO is primarily between 400 and $700 \mathrm{hPa}$ (the peak sensitivity is at approximately $550 \mathrm{hPa}$ ) and for precipitating clouds the sensitivity is primarily between 300 and $600 \mathrm{hPa}$ (the peak sensitivity for precipitating clouds is at $450 \mathrm{hPa}$ ). The effects of these varying sensitivities are apparent in the example retrievals shown in the bottom panels of Fig. 1. Estimated $\mathrm{HDO} / \mathrm{H}_{2} \mathrm{O}$ ratios in clear sky and nonprecipitating clouds show variations between $400 \mathrm{hPa}$ and $825 \mathrm{hPa}$, whereas the isotopic composition for tropical precipitating clouds only varies around $500 \mathrm{hPa}$.

\section{Results and discussion}

\subsection{Case study relating TES observed tropical clouds to isotopic composition of water vapor}

We present a case study that compares TES cloud distributions with two-dimensional observed cloud distributions from the Moderate Resolution Imaging Spectrometer (MODIS) imager onboard the Aqua satellite (Barnes et al., 


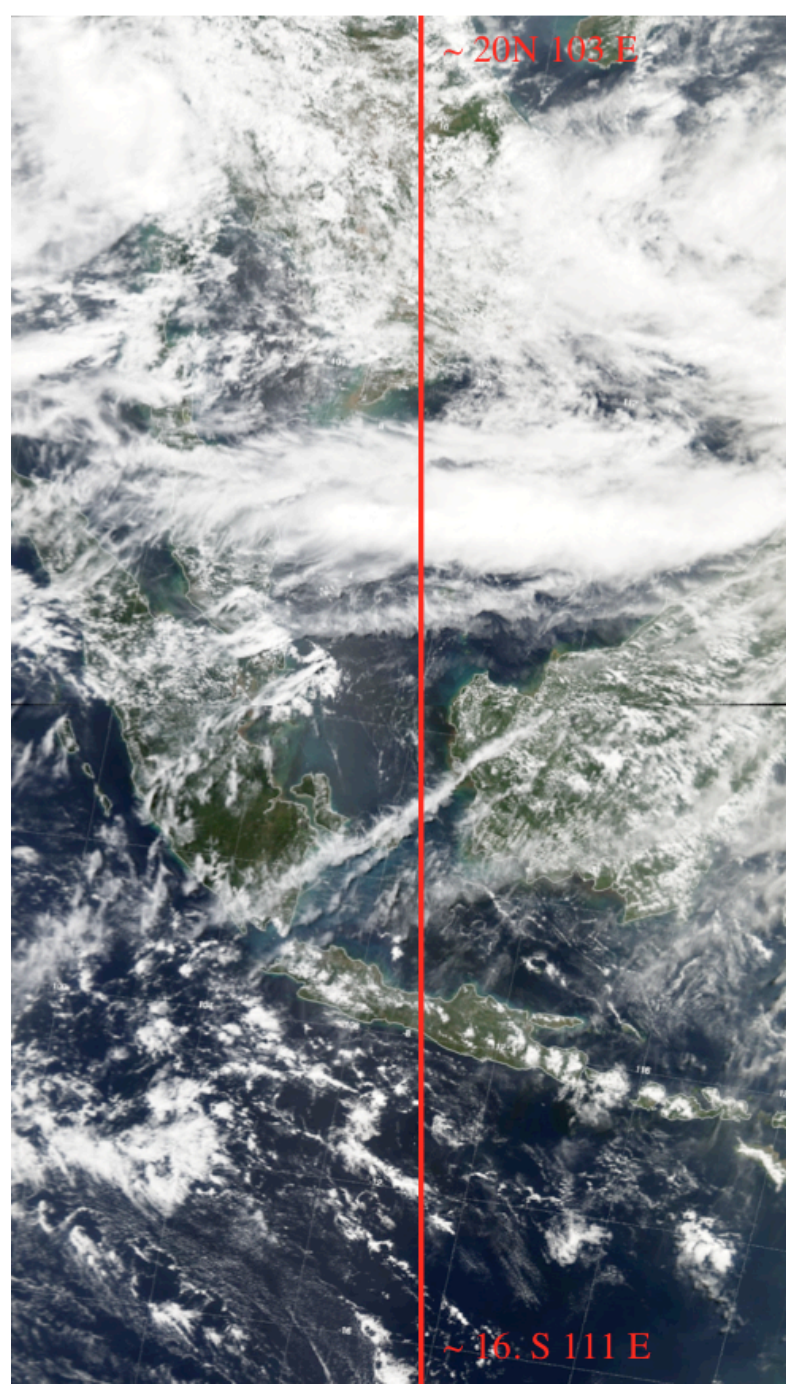

Fig. 2. An example of a visible image composite derived from the MODIS imager onboard the Aqua satellite during 22 July 2007.

1998). This comparison is used to corroborate the clouds definitions described in the previous section for TES (e.g., clear sky, nonprecipitating, boundary layer and precipitating clouds) and also to provide additional information on the meteorology that affects the water vapor amount and isotopic composition of water vapor observed by TES. Two of the MODIS L1B granules, taken over Indonesia, have been warped so that the images from bottom to top follow the curved orbit track. A TES "step-and-stare", which is a set of nadir footprint spaced about $35 \mathrm{~km}$ apart, was conducted during this same time and the approximate orbit location of this set of observations is shown as a vertical red line over the MODIS imagery.

The MODIS imagery shows clear sky with scattered clouds south of the equator and several cloud systems associated with deep convection north of the equator. The TES observations of the CTP and effective COD, corresponding to the orbit shown in Fig. 2, are shown in Fig. 3. The TES data show that the CTP of the deep convective cloud near $5^{\circ} \mathrm{N}$ are approximately $200 \mathrm{hPa}$. At latitudes between $10^{\circ} \mathrm{N}$ and $15^{\circ} \mathrm{N}$ are clouds related to convective outflow (as seen in the MODIS image) with CTP of between 800 and $400 \mathrm{hPa}$ (Fig. 3). These clouds would also be classified as precipitating clouds using the ISCCP definitions.

The water vapor amount and $\delta D$ values along the stepand-stare are shown in Fig. $3 \mathrm{c}$ and $\mathrm{d}$ for the $500 \mathrm{hPa}$, respectively. The vertical resolution of the water profiles is approximately $3 \mathrm{~km}$, indicating good sensitivity to water at this level. The TES $\delta D$ values are primarily sensitive to the air parcels between $300 \mathrm{hPa}$ and $850 \mathrm{hPa}$ depending on CTP (Worden et al., 2006), which will be shown in next section. However, the vertical resolution of the TES HDO/ $\mathrm{H}_{2} \mathrm{O}$ measurements is approximately $6-8 \mathrm{~km}$, consequently, these TES estimates cannot distinguish, for example, the variations of the $\mathrm{HDO} / \mathrm{H}_{2} \mathrm{O}$ ratio at $300 \mathrm{hPa}$ from variations of the $\mathrm{HDO} / \mathrm{H}_{2} \mathrm{O}$ ratio at $800 \mathrm{hPa}$. For this reason, we show the estimated $\delta D$ values along the orbit track at $500 \mathrm{hPa}$ as almost all the observations are sensitive to the $\delta D$ values at this altitude. However, we show column averages of the TES $\mathrm{H}_{2} \mathrm{O}$ and $\delta D$ in subsequent sections in order to better relate total water amounts to variations in the $\delta D$. As discussed in the subsequent section the choice of the pressure range for the column will depend on the cloud type.

The air parcels south of $-10^{\circ}$ in Fig. 3 are much drier than the air parcels in and around the precipitating clouds and show a contrast in the relationship among clouds, water vapor, and the isotopic composition of the water vapor. For example, at $-18^{\circ}$, the water vapor is near $0.001 \mathrm{~g} / \mathrm{kg}$, but the isotopic composition is relatively high, near $-200 \%$; these data are near very thin clouds with a cloud top of approximately $600 \mathrm{hPa}$. Near $-3^{\circ}$, the air is relatively dry, approximately $1 \mathrm{~g} / \mathrm{kg}$ but also very isotopically depleted underneath high cirrus (cloud-top pressure near $200 \mathrm{hPa}$, but cloud optical depth less than 1.0). The lower tropospheric clouds indicate low-level convection of boundary layer air (e.g., Lee et al., 2009). Although the air parcels are relatively dry in and around these different cloud types, these dynamical processes of descent and uplift would mix isotopically depleted air from the upper troposphere (Webster and Heymsfield, 2003; Risi et al., 2008a), with relatively isotopically enriched air from the boundary layer. The northern part of this data shows precipitating clouds, relatively high water amounts but also relatively depleted air parcels. This behavior of increased water vapor with more depleted air parcels also indicates precipitation as expected from the MODIS imagery and TES clouds. In the following sections we examine these relationships between clouds, water vapor, and isotopic composition on a more climatological time scale. 


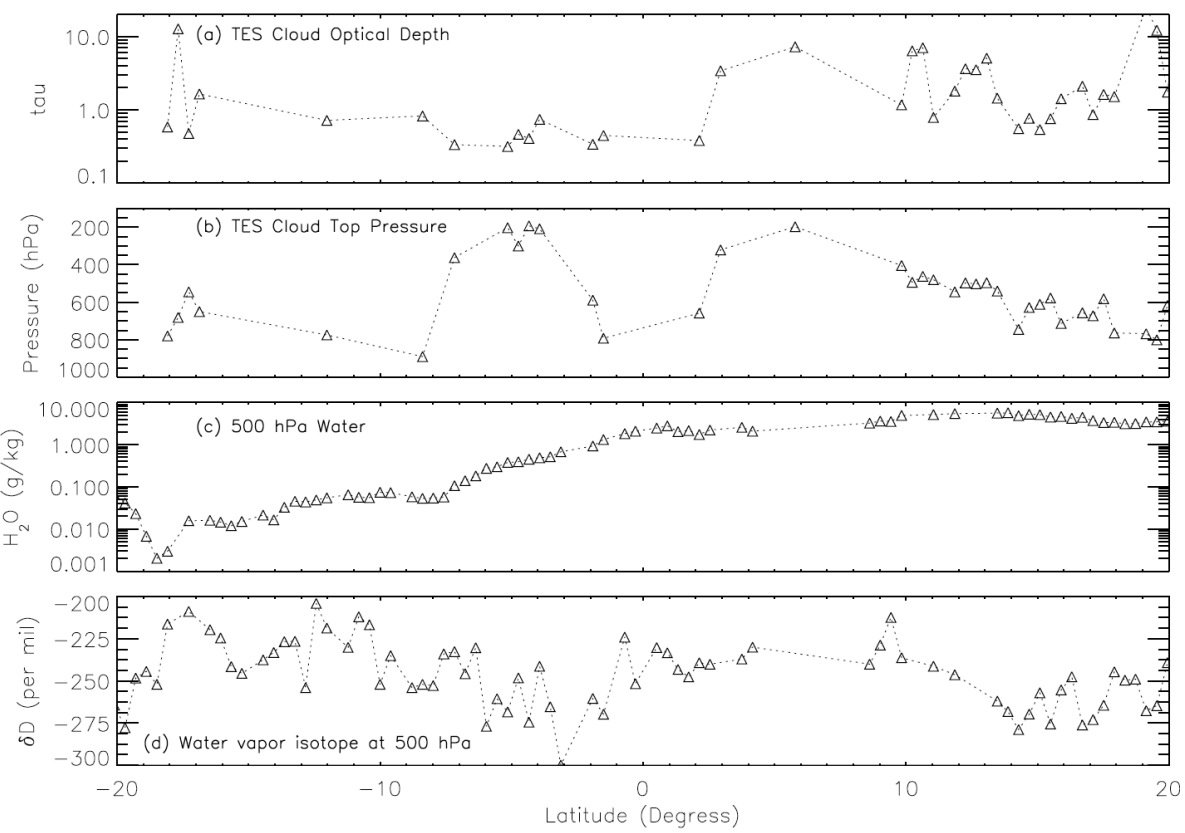

Fig. 3. The TES observations of (a) effective COD, (b) CTP, (c) water vapor amount at $500 \mathrm{hPa}$, and (d) isotopic composition of water vapor at $500 \mathrm{hPa}$, corresponding to the orbit shown in Fig. 2. Only cloudy conditions are presented in (a) and (b).

\subsection{Tropical distributions of clouds, water vapor and its isotope}

In this section, we present longitudinal distributions of cloud types, water vapor, and its isotopic composition observed by TES in order to examine how water vapor and its isotopic composition respond to different moist environments thus informing about the distribution of moist processes at different locations in the tropical ocean (Fig. 4). Figure 4a and b show the frequency of longitudinal distributions $\left(f_{1}\right)$ for clear sky (blue cross in Fig. 4a), in the regions of nonprecipitating clouds (green asterisk in Fig. 4a), in the regions of boundary layer clouds (cyan square in FIg. 4b), and in the regions of precipitating clouds (red diamond in Fig. 4b) during JJA. The fractions of both nonprecipitating and boundary layer clouds have peaks around $-90^{\circ}$ and precipitating clouds have a peak around $130^{\circ}$. Two regions, the Caribbean $\left(-80^{\circ}\right)$ and Indonesia $\left(120^{\circ}\right)$, have high water vapor amount, which is consistent with the observed relative increase in the fraction of precipitating clouds distributions (Fig. 4b).

Comparisons of the longitudinal variability of the isotopic composition to water vapor amount illustrate key differences in the processes affecting vapor in these regions. For example, two places (marked with two cyan arrows) in the eastern and western pacific are both isotopically depleted, but the western pacific is relatively moist while the eastern pacific is relatively dry. Air parcels over the eastern Pacific are significantly influenced by downward motion associated with the Walker circulation; this brings dry air (Kubar et al., 2007), which is presumably isotopically depleted into the lower tro- posphere. We discount the effect of vertical distribution of the TES sensitivity on this conclusion because, as discussed in the Appendix, the vertical sensitivity appears to bias our estimate towards less depleted values due to the influence of the a priori constraints at low altitudes. However, another possible explanation is that increased stratocumulus reduces mixing between the ocean and the lower troposphere. As discussed in the previous section, frequent convection and re-mixing of air parcels back into precipitating clouds controls the vapor in the western Pacific resulting in isotopically depleted air.

In contrast, relatively high vapor but relatively moderate isotope ratios are observed over the Caribbean at $-80^{\circ}$. This region is significantly influenced by each cloud type indicated a variety of processes affecting tropospheric moisture. Cumulus clouds indicate significant shallow convection (Johnson et al., 1999), which brings fresh vapor from just above the ocean surface to the lower troposphere, but precipitating clouds isotopically depletes the observed air parcels. The mean distribution in this region therefore appears to be a mixture of this fresh vapor followed by depletion due to precipitation.

The isotopic composition of oceanic water vapor around continents (the Amazon at $-50^{\circ}$ and tropical Africa at $40^{\circ}$ and $50^{\circ}$ ) is relatively enriched in heavy isotope although the distributions of clouds and water vapor vary strongly over these different regions. These air parcels can be originated from the nearby continents or by relatively frequent mixing between the boundary layer and the lower troposphere. 

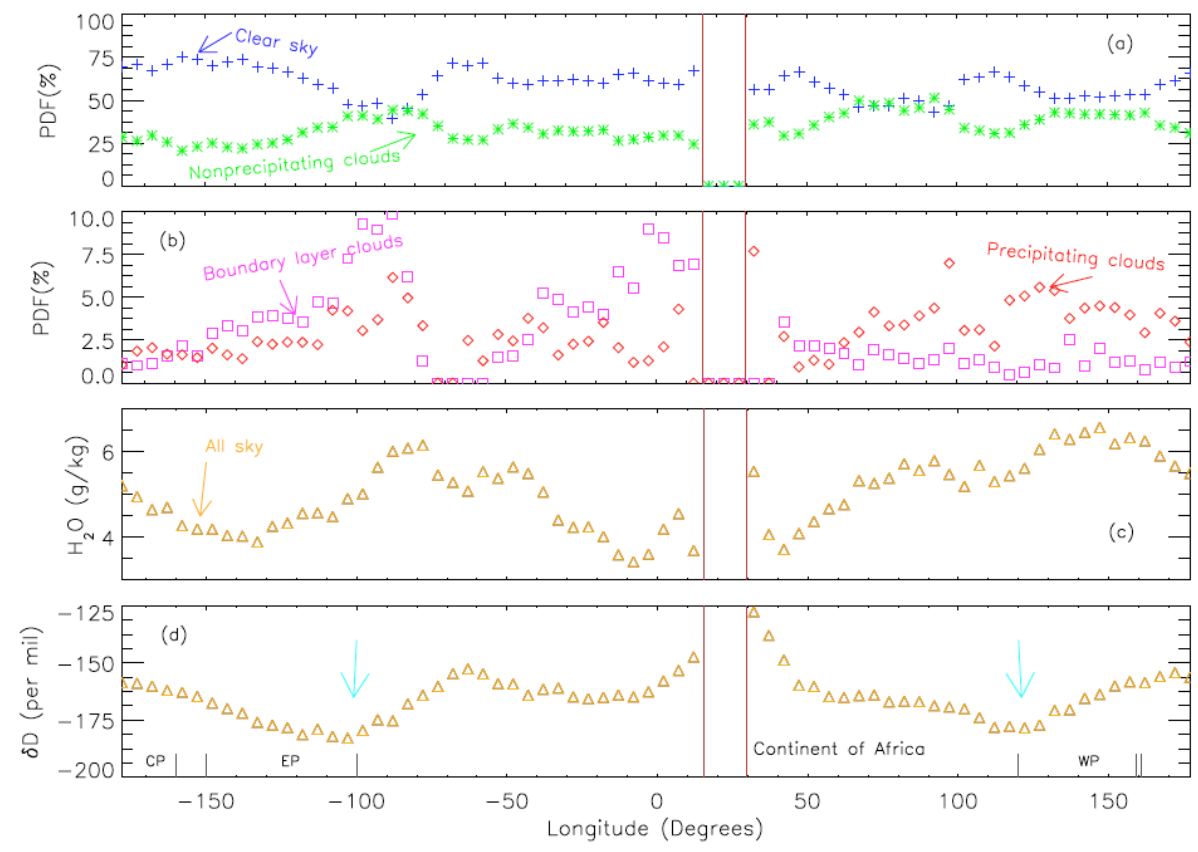

Fig. 4. Longitudinal distributions of cloud (a and b), water vapor (c) and its isotope (d) over tropical ocean. There is no tropical oceanic data point between $15^{\circ}$ to $35^{\circ}$. (a) Clear sky (blue cross) and nonprecipitating clouds (green asterisk). (b) Boundary layer clouds (cyan square) and precipitating clouds (red diamond). (c) Water vapor $(\mathrm{g} / \mathrm{kg}$ ) for all sky conditions (d) Water vapor isotope (\%o). The two magenta arrows indicate isotopically depleted regions. The cloud types were classified based on the ISCCP. Longitudinal mean $\left(-15^{\circ}<\right.$ Latitude $\left.<15^{\circ}\right)$ were binned at $5^{\circ}$ longitudes.

\subsection{Relationship between water vapor and $\delta D$ over tropical ocean}

In this section, we explore distributions of the isotopic composition of water as compared to a theoretical Rayleigh distillation processes and mixing models for different cloud types and at different tropical locations in order to further elucidate the moist processes and sources at different locations in the tropics. These distributions are shown for each cloud type and different tropical regions in Figs. 5 and 6. The lower line (orange dotted) in each figure shows what we would expect for an air parcel originating from the local ocean surface at the mean local ocean temperature followed by condensation in the lower troposphere and upper planetary boundary layer. The top line (orange solid) shows a mixing model in which dry depleted air is mixed in with vapor from the nearby ocean. The analytical form for these models is also described in the supplemental material of Worden et al. (2007).

In order to show how water vapor and its isotopic composition vary with different places, or cloud conditions over the tropical ocean, Figure 5 illustrates the relationship between water vapor and its isotopic composition observed in the environments of both clear sky (blue solid) and nonprecipitating clouds (green solid). Distributions of water vapor and its isotopic composition are examined over the Western Pacific (WP: $-15^{\circ} \sim 15^{\circ} \mathrm{N}, 120^{\circ} \sim 160^{\circ} \mathrm{E}$ ), Central Pacific $\left(\mathrm{CP}:-15^{\circ} \sim 15^{\circ} \mathrm{N}, 160^{\circ} \mathrm{E} \sim-160^{\circ}\right.$ ), Eastern Pa- cific (EP: $-15^{\circ} \sim 15^{\circ} \mathrm{N},-150^{\circ} \sim-100^{\circ}$ ) and Africa (Af: $\left.-15^{\circ} \sim 15^{\circ} \mathrm{N},-20^{\circ} \sim 50^{\circ} \mathrm{E}\right)$ in clear sky and nonprecipitating clouds. Most of the observations from clear sky, and in the regions of nonprecipitating clouds, are reasonably wellconstrained by the theoretical curves for Rayleigh distillation from moisture originating over an oceanic source, with initial $\delta D$ values of $-79 \%$ (orange dotted line) and the curve representing mixing of air parcels.

The Rayleigh distillation and mixing models for clear sky and nonprecipitating clouds show several similar characteristics (Table 2). The $\delta D$ values are similar for each distribution but the nonprecipitating cloud distribution are more moist than the clear sky distributions (e.g., Kahn et al., 2009). Despite the differences in water vapor amounts, the similarity in the $\delta D$ distributions and the correlations indicate that air parcels associated with clear sky are linked to the nonprecipitating clouds and have undergone similar moist processes such as shallow convection (Steven, 2005; Lee et al., 2009). This relationship is apparent in the distributions for clear sky and nonprecipitating clouds except WP although the correlation between $\delta D$ and water amount is slightly negative for nonprecipitating clouds $(r=-0.12)$. This negative correlation suggests that these air parcels in the regions of nonprecipitating clouds are exposed to recent precipitation; this interpretation is also consistent with the observations of convective clouds in this region. 

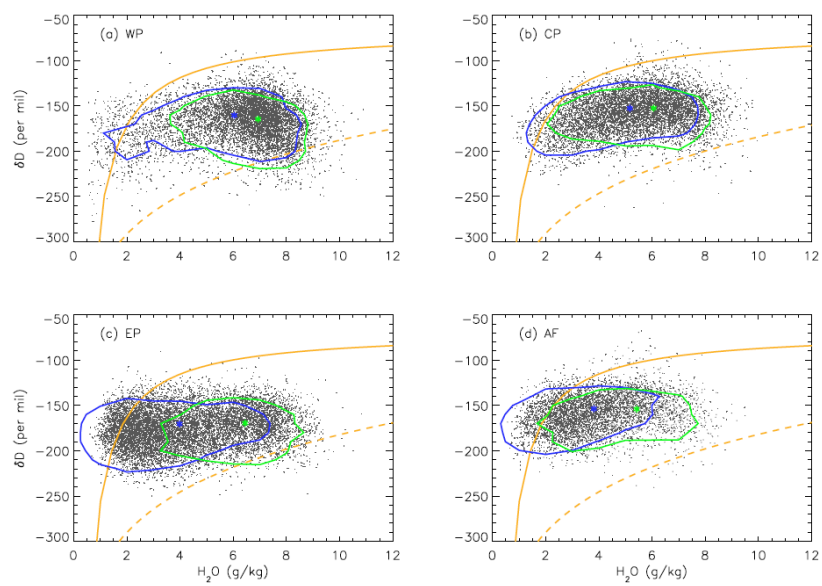

Fig. 5. Bivariate plots of water vapor versus its isotope during JJA over tropical ocean (charcoal dots). Each solid line represents $95 \%$ of a probability density function for clear sky (blue) and nonprecipitating clouds (green). The symbols “*” represent mean values of water vapor and its isotope. Solid evaporation line depicts turbulent mixing of water vapor from the saturated layer at the ocean surface into a drier air parcel aloft. A Rayleigh distillation model (dotted) describes isotopic depletion as vapor is lost to precipitation. (a) Western Pacific $\left(5^{\circ}-15^{\circ} \mathrm{N}, 120^{\circ}-160^{\circ} \mathrm{E}\right)$, (b) Central pacific $\left(5^{\circ}-15^{\circ} \mathrm{N}, 160^{\circ} \mathrm{E}-160^{\circ} \mathrm{W}\right),\left(\right.$ c) Eastern Pacific $\left(5^{\circ}-15^{\circ} \mathrm{N}\right.$, $\left.150^{\circ}-100^{\circ} \mathrm{W}\right)$ and $(\mathbf{d})$ Africa $\left(5^{\circ}-15^{\circ} \mathrm{N}, 50^{\circ} \mathrm{E}-25^{\circ} \mathrm{W}\right)$

Table 2. The mean of TES measured water vapor and $\mathrm{HDO} / \mathrm{H}_{2} \mathrm{O}$ ratio $(850-500 \mathrm{hPa})$ from clear sky and nonprecipitating clouds in the three regions, WP, CP and EP. Clear sky and nonprecipitating clouds values are separated by commas.

\begin{tabular}{lll}
\hline & $\mathrm{g} / \mathrm{kg}$ & $\delta D(\% \circ)$ \\
\hline WP (clear sky, nonprecipitating clouds) & $6.0,6.8$ & $-165.9,-170.1$ \\
CP (clear sky, nonprecipitating clouds) & $5.0,6.0$ & $-158.0,-157.9$ \\
EP (clear sky, nonprecipitating clouds) & $3.8,6.3$ & $-175.9,-175.0$ \\
\hline
\end{tabular}

Two other differences are apparent in these distributions. The EP distribution is relatively drier and more isotopically depleted than the CP distribution, suggesting that subsiding dry air or lack of mixing between the troposphere and ocean affect the EP air parcels more than the CP (Fig. 5b, c and Table 2) (Kubar et al., 2007). Finally, The clear sky Af air parcels are relatively dry (clear sky, $3.6 \mathrm{~g} / \mathrm{kg}$ and nonprecipitating clouds $5.5 \mathrm{~g} / \mathrm{kg}$ ) and enriched in heavy isotopes (clear sky, $-159.2 \%$ and nonprecipitating clouds $-159.5 \%$ ) (Fig. 5d). The Af region is relatively dry, but relatively enriched in heavy isotopes, which indicates frequent mixing with fresh oceanic vapor or vapor from evapotranspiration and less subsequent precipitation then the other regions. (Flanagan et al., 1991; Worden et al., 2007; Brown et al., 2008).
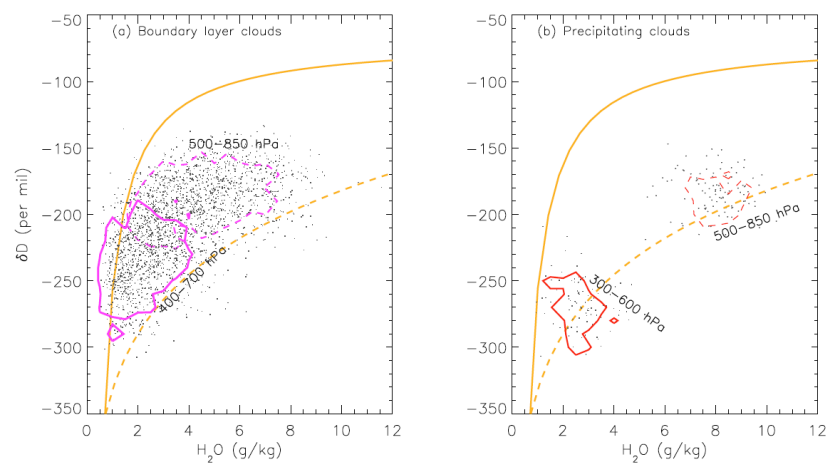

Fig. 6. (a) TES observations of water vapor vs. its isotope for boundary layer clouds (b) TES observations for precipitating clouds. Dashed contour lines represent typical TES observations averaged between 500 and $800 \mathrm{hPa}$. Solid contour lines represent averaged TES measurements of the most sensitive vertical range for boundary layer clouds $(400-700 \mathrm{hPa})$ and precipitating clouds $(300-600 \mathrm{hPa})$.

Figure 6a shows the $\delta D$ versus $\mathrm{H}_{2} \mathrm{O}$ distribution for boundary clouds such as strato-cumulus and stratus. Two distributions are shown, one constructed from averages of $\mathrm{HDO}$ and $\mathrm{H}_{2} \mathrm{O}$ between 500 and $850 \mathrm{hPa}$ and one constructed from averages of $400-700 \mathrm{hPa}$. The first distribution is for comparison against the clear sky and nonprecipitating cloud distributions and shows that the air above boundary layer clouds is more isotopically depleted than air parcels associated with clear sky and nonprecipitating clouds. However, the second distribution $(400-700 \mathrm{hPa})$ shows the altitude region where this data is most sensitive. We can conclude from either distribution that the TES observations above boundary layer clouds are well constrained by local mixing and Rayleigh condensation. However, the extra isotopic depletion as shown in Table 1 indicates an additional set of moist processes. Regions of stratocumulus are characterized by a relatively shallow, cool, and moist boundary layer that is capped by a much warmer and drier subsiding atmosphere (e.g., Klein and Hartmann, 1993; Steven, 2005). This process makes the free-troposphere drier and more depleted in heavy isotope than other nonprecipitating clouds environment due to less frequent mixing between the boundary layer and the free-troposphere (Fig. 6a, see Table 1). Feng et al. (2009) shows that surface precipitation measurements in these regions are isotopically enriched; however these measurements indicate strong evaporation from the surface which leads to the formation of boundary layer clouds in the regions of subsiding air. These measurements of relatively isotopically depleted free tropospheric vapor and relatively enriched surface precipitation are consistent in explaining the moist processes forming these clouds.

Figure $6 \mathrm{~b}$ shows the $\delta D$ versus $\mathrm{H}_{2} \mathrm{O}$ distribution for tropical precipitating clouds. Two distributions are shown, one constructed from averages of $\mathrm{HDO}$ and $\mathrm{H}_{2} \mathrm{O}$ between 500 
and $850 \mathrm{hPa}$ and one constructed from averages of 300$600 \mathrm{hPa}$. The first distribution is for comparison to the clearsky and non-precipitating cloud distributions. However, as shown in Fig. 1, the TES data for these clouds have little sensitivity to the lower altitudes. Both distributions show that the water vapor above these clouds has isotopic values that are more depleted than can be explained by local Rayleigh distillation with the mean of this distribution near the Rayleigh model curve. The implication of these lower $\delta D$ values with significant moisture content and clouds related to outflow from organized convective suggest that the vapor has been re-cycled by the processing related to organized convection (Worden et al., 2007). As the vapor is recycled, it can either re-evaporate or exchange isotopes with the surrounding moisture; both of these processes will result in extra fractionation of the water vapor (e.g., Lawrence et al., 2004 and Risi et al., 2008b) and hence lower $\delta D$ for the same water concentration. This moisture recycling of the vapor was discussed in these papers as one aspect that gives rise to the "amount effect", in which the isotopic composition of precipitation gradually becomes more depleted as precipitation increases.

\section{Summary and implications}

In this study, we characterize the distribution of summertime tropical water vapor above the ocean, its isotopic composition, and co-located cloud properties using measurements from the Aura TES instrument. We examine linkages between these distributions using simple isotopic mixing and precipitation models. This analysis accounts for the capability of the TES instrument to distinguish between different cloud types and for the sensitivity of the TES water vapor isotope measurements, which also depend on cloud optical properties.

The cloud types are based on definitions from the ISCCP for explaining tropical tropospheric moisture distributions. We sub-divide the ISCCP categories into more general categories of nonprecipitating clouds (e.g., cumulus and cirrus), boundary layer clouds (e.g. stratus and stratocumulus) and precipitating clouds associated with deep convection, as well as clear sky. These definitions are chosen (1) in order to best match the TES measured cloud optical properties to the ISCCP cloud definitions and (2) because the sensitivity of the TES water isotope measurements varies with the optical properties of these different cloud types. For example, the peak sensitivity for clear sky and non-precipitation clouds is at approximately $675 \mathrm{hPa}$. The peak sensitivity for boundary layer clouds is at approximately $550 \mathrm{hPa}$ and the peak sensitivity for precipitating clouds is at $450 \mathrm{hPa}$.

Distributions of water vapor and its isotopic composition are examined over the Western Pacific (WP), Central Pacific (CP), Eastern Pacific (EP) and Africa (Af) in clear sky and nonprecipitating clouds. WP is moist and slightly anti- correlated between water vapor and its isotopic composition for nonprecipitating clouds, indicating observations in the region of nonprecipitating clouds are affected by nearby convective precipitating clouds. EP is relatively dry and more depleted in heavy isotope than $\mathrm{CP}$, suggesting that subsiding air affects or lack of mixing between the troposphere and ocean affect these air parcels. The Af region is relatively dry, but relatively enriched in heavy isotopes, which indicates frequent mixing with fresh oceanic vapor or vapor from evapotranspiration and less subsequent precipitation then the other regions.

Observations in the region of nonprecipitating clouds have more water vapor than observations in the region of clear sky does, but they have similar isotopic composition, which indicates the processes controlling cumulus clouds such as shallow convection also controls the distribution of lower free tropospheric vapor. Furthermore, cumulus clouds may have little precipitation or else we would expect significantly lighter isotopic values around regions of cumulus. Observations in the region of boundary layer clouds are more depleted than both clear sky and nonprecipitating clouds, implying subsidence or less frequent mixing between boundary layer and lower troposphere. Observations in the region of precipitating clouds are more depleted than clear sky and nonprecipitating clouds and have much more water vapor, indicating an additional fractionation process such as rainfall evaporation, or isotope exchange between raindrops and the surrounding air during convective activities. These distributions will be used in subsequent comparisons of climate models to the TES water isotope observations in order to diagnose the models moist processes (Noone and Simmonds, 2004; Yoshimura et al., 2008).

\section{Appendix A}

\section{Impact of bias error from choice of a priori constraint (smoothing error) for interpreting differences in isotopic composition between different cloud regimes}

The intent of this Appendix is to determine whether the depleted values observed for "boundary layer cloud" scenes, relative to clear sky scenes, is due to a physical process or simply because the measurement sensitivity for these scenes is at a higher altitude where the isotopic composition is more depleted. The vertical resolution and choice of a priori constraint used to regularize remotely sensed estimates imparts an uncertainty called smoothing error, as discussed in Rodgers (2000), which affects conclusions about the magnitude of differences between two estimates. Smoothing error can have both a random and bias component (e.g., Kulawik et al., 2010). Typically the smoothing error is less than 15 parts per mil relative to SMOW for a column averaged value between 825 and $400 \mathrm{hPa}$ and depends on the vertical resolution 
of the estimate (Worden et al., 2006). In this appendix we estimate the bias component of the smoothing error for comparisons between two distributions of remotely sensed estimates in which the averaging kernels for these estimates are moderately different but have overlapping sensitivities. In particular we estimate the bias error for the comparison between the mean of the clear-sky $\delta D$ values and the mean of the boundary layer cloud $\delta D$ values. Note that in the current TES products, smoothing error is included in the total error for the $\mathrm{HDO} / \mathrm{H}_{2} \mathrm{O}$ ratio but is not easily calculated from the current TES products for the ratio due to an error in the products algorithm related to the cross-terms in the $\mathrm{H}_{2} \mathrm{O}$ and HDO error covariances. In the next version of the TES products it will be straightforward to calculate smoothing error for the ratio.

If each estimate ( $\hat{\boldsymbol{x}}_{c}$ for clear sky and $\hat{\boldsymbol{x}}_{b}$ for boundary layer clouds) is close to the true state, its dependence on the choice of constraint vector, constraint matrix and true state can be described by the linear estimate (Rodger, 2000; Worden et al., 2006).

$\hat{\boldsymbol{x}}_{c}=\boldsymbol{x}_{a}+\boldsymbol{A}_{c}\left(\boldsymbol{x}-\boldsymbol{x}_{\mathrm{a}}\right)$

$\hat{\boldsymbol{x}}_{b}=\boldsymbol{x}_{a}+\boldsymbol{A}_{b}\left(\boldsymbol{x}-\boldsymbol{x}_{\mathrm{a}}\right)$,

where $\mathbf{x}$ is the "true" full state vector, $\mathbf{x}_{a}$ is the constraint state vector (the $\mathrm{HDO}$ and $\mathrm{H}_{2} \mathrm{O}$ profiles), and $\mathbf{A}_{c}$ and $\mathbf{A}_{b}$ are the averaging kernels for the two estimates (e.g., averaging kernels representative of clear sky or boundary layer cloud conditions). We intend to investigate the bias error in a comparison of these two estimates if the averaging kernels overlap but are moderately different. This can be accomplished by subtracting Eq. A1 from Eq. A2 and assuming the true state is the same for both estimates. This will account for how the different vertical resolution, as described by the averaging kernel matrix, affects the final estimate; this comparison follows Rodgers and Connor (2003) for comparisons of two remotely sensed measurements of the same air mass in Eq. A3:

$\hat{\boldsymbol{x}}_{b}-\hat{\boldsymbol{x}}_{c}=\left(\boldsymbol{A}_{b}-\boldsymbol{A}_{c}\right)\left(\boldsymbol{x}-\boldsymbol{x}_{a}\right)$

In order to estimate the bias error due to the TES vertical resolution for comparisons of clear sky to boundary layer clouds, we construct an average of the averaging kernels for boundary layer clouds $\left(\mathbf{A}_{b}\right)$ and clear sky $\left(\boldsymbol{A}_{c}\right)$, respectively. The difference between two profiles $\left(\hat{\boldsymbol{x}}_{b}-\hat{\boldsymbol{x}}_{c}\right)$, averaged over the pressure region of interest (for example, 850 and $500 \mathrm{hPa}$ ) is our estimated bias error due to the TES vertical resolution.

We assume two $\mathrm{HDO} / \mathrm{H}_{2} \mathrm{O}$ profiles $(5 \%$ and $2.5 \%$ depleted compared to the a priori constraint) as the true state vector $(x)$ in order to account for the expected depletion of the air parcels above the tropical boundary layer clouds relative to the a priori constraint. Note that our assumption about the relative isotopic composition of the free troposphere over boundary layer clouds will affect our bias estimate.

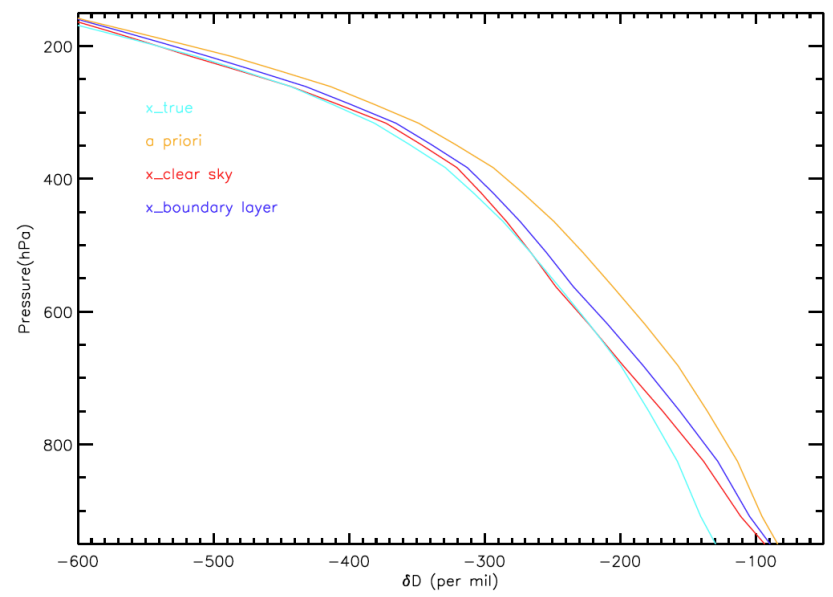

Fig. A1. An example of simulated retrievals of $\mathrm{HDO} / \mathrm{H}_{2} \mathrm{O}$ profiles for the different cloud conditions. $5 \%$ depleted $\mathrm{HDO} / \mathrm{H}_{2} \mathrm{O}$ profile was assumed as the true state vector $(\boldsymbol{x})$ in this calculation.

Figure A1 shows simulated results of $\mathrm{HDO} / \mathrm{H}_{2} \mathrm{O}$ profiles for two different cloud regimes. Between 850 and $500 \mathrm{hPa}$, the bias errors $\left(\hat{\boldsymbol{x}}_{b}-\hat{\boldsymbol{x}}_{c}\right)$ are $12.7 \%$ and $6.4 \%$ for $5 \%$ and $2.5 \%$ depletion of true state vector, respectively, which means that estimates of the isotopic composition of the free tropospheric above boundary layer clouds are biased toward the a priori constraint by $12.7 \%$ and $6.4 \%$ respectively, consistent with the magnitude of the smoothing error. Based on this analysis, the estimates of the mean isotopic difference between clear sky and boundary layer clouds could be larger (by up to 12.7\%o) due to the impact of vertical resolution, that is, we are underestimating the difference.

Acknowledgements. The research described in this paper was carried out at the Jet Propulsion Laboratory, California Institute of Technology, under a contract with the National Aeronautics and Space Administration. Support from NASA funding under 07-NEWS07-20 is gratefully acknowledged. We thank Matthias Schneider for his comments. Copyright 2010. All rights reserved.

Edited by: T. Röckmann

\section{References}

Barnes, W. L., Pagano, T. S., and Salomonson, V. V.: Prelaunch characteristics of the Moderate Resolution Imaging Spectrometer (MODIS) on EOS-AM1, IEEE Trans. Geosci. Remote Sens., 36, 1088-1100, 1998.

Beer, R.: TES on the Aura mission: Scientific objectives, measurements, and analysis overview, IEEE Trans. Geosci. Remote Sens., 44(5), 1102-1105, 2006.

Bony, S., Risi, C., and Vimeux, F.: Influence of convective processes on the isotopic composition $\left(\delta^{18} \mathrm{O}\right.$ and $\delta D)$ of precipitation and water vapor in the tropics: 1 . Radiative-convective equilibrium and Tropical Ocean-Global Atmospheric-Coupled Ocean-Atmosphere Response Experiment 
(TOGA-COARE) simulations, J. Geophys. Res., 113, D19305, doi:10.1029/2008JD009942, 2008.

Brown, D., Worden, J., and Noone, D.: Comparison of atmospheric hydrology over convective continental regions using water vapor isotope measurements from space, J. Geophys. Res., 113, D15124, doi:10.1029/2007JD009676, 2008.

Ciais, P. and Jouzel, J.: Deuterium and oxygen 18 in precipitation: Isotopic model, including mixed cloud processes, J. Geophys. Res., 99, D8, 16793-16803, 1994.

Dessler, A. E. and Sherwood, S. C.: A model of HDO in the tropical tropopause layer, Atmos. Chem. Phys., 3, 2173-2181, doi:10.5194/acp-3-2173-2003, 2003.

Eldering, A., Kulawik, S. S., Worden, J., Bowman, K., and Osterman, G.: Implementation of cloud retrievals for TES atmospheric retrievals: 2 . Characterization of cloud top pressure and effective optical depth retrievals, J. Geophys. Res., 113, D16S37, doi:10.1029/2007JD008858, 2008.

Feng, X., Faiia, A. M., and Posmentier, E. S.: Seasonality of isotopes in precipitation: A global perspective, J. Geophys. Res., 114, D08116, doi:10.1029/2008JD011279, 2009.

Flanagan, L. B., Comstock, J. P., and Ehleringer, J. R.: Comparison of modeled and observed environmental influences on the stable oxygen and hydrogen isotope composition of leaf water in Phaseolus vulgaris L, Plant Physiol., 96, 588-596, 1991. v Frankenberg, C., Yoshimura, K., Warneke, T., Aben, I., Butz, A., Deutscher, N., Griffith, D., Hase, F., Notholt, J., Schneider, M., Schrijver, H., and Röckman, T.: Dynamic processes governing lower-tropospheric $\mathrm{HDO} / \mathrm{H}_{2} \mathrm{O}$ ratios as observed from space and ground, Science, 325, 1374-1377, 2009.

Gat, J. R.: Oxygen and hydrogen isotopes in the hydrological cycle, Annu. Rev. Earth Planet. Sci., 24, 225-262, 1996.

Gat, J. R.: Atmospheric water balance-the isotopic perspective, Hydrol. Process., 14, 1357-1369, 2000.

Gedzelman, S., Lawrence, J., Gamache, J., Black, M., Hindman, E., Black, R., Dunion, J., Willoughby, H., and Zhang, X.: Probing hurricanes with stable isotopes of rain and water vapor, Mon. Weather Rev., 131, 1112-1127, 2003.

Gettelman, A., and Webster, C. R.: Simulations of water isotope abundances in the upper troposphere and lower stratosphere and implications for stratosphere troposphere exchange, J. Geophys. Res., 110, D17301, doi:10.1029/2004JD004812, 2005.

Herbin, H., Hurtmans, D., Turquety, S., Wespes, C., Barret, B., Hadji-Lazaro, J., Clerbaux, C., and Coheur, P.-F.: Global distributions of water vapour isotopologues retrieved from IMG/ADEOS data, Atmos. Chem. Phys., 7, 3957-3968, doi:10.5194/acp-7-3957-2007, 2007.

IAEA/WMO, Global Network of Isotopes in Precipitation, The GNIP Database, available online at: http://isohis.iaea.org), 2006.

Johnson, R. H., Rickenbach, T. M., Rutledge, S. A., Ciesielsku, P. E., and Schubert, W. H.: Trimodal characteristics of tropical convection, J. Clim., 12, 2397-2418, 1999.

Kahn, B. H., Gettelman, A., Fetzer, E. J., Eldering, A., and Liang, C. K.: Cloudy and clear-sky relative humidity in the upper troposphere observed by the A-train, J. Geophys. Res., 114, D00H02, doi:10.1029/2009JD011738, 2009.

Klein, S. A. and Hartmann, D. L.: The seasonal cycle of low stratiform clouds, J. Clim., 6, 1587-1606, 1993.

Kulawik, S. S., Worden, J., Eldering, A., Bowman, K., Gunson, M., Osterman, G. B., Zhang, L., Clough, S. A., Shephard, M. W., and
Beer, R.: Implementation of cloud retrievals for Tropospheric Emission Spectrometer (TES) atmospheric retrievals: part 1. Description and characterization of errors on trace gas retrievals, J. Geophys. Res., 111, D24204, doi:10.1029/2005JD006733, 2006.

Kulawik, S. S., Jones, D. B. A., Nassar, R., Irion, F. W., Worden, J. R., Bowman, K. W., Machida, T., Matsueda, H., Sawa, Y., Biraud, S. C., Fischer, M. L., Jacobson, A. R.: Characterization of Tropospheric Emission Spectrometer (TES) $\mathrm{CO}_{2}$ for carbon cycle science, Atmos. Chem. Phys., 10, 5601-5623, doi:10.5194/acp-10-5601-2010, 2010.

Kuang, Z., Toon, G. C., Wennberg, P. O., and Yung Y. L.: Measured $\mathrm{HDO} / \mathrm{H}_{2} \mathrm{O}$ ratios across the tropical tropopause, Geophys. Res. Lett., 30(7), 1372, doi:10.1029/2003GL017023, 2003.

Kubar, T. L., Hartmann, D. L., and Wood, R.: Radiative and convective driving of tropical high clouds, J. Clim., 20, 5510-5526, 2007.

Lawrence, J. R. and Gedzelman, S. D.: Low stable isotope ratios of tropical cyclone rains, Geophys. Res. Lett., 23, 527-530, 1996.

Lawrence, J. R., Gedzelman, S. D., Dexheimer, D., Cho, H.K., Carrie, G. D., Gasparini, R., Anderson, C. R., Bowman, K. P., and Biggerstaff, M. I.: Stable isotopic composition of water vapor in the tropics, J. Geophys. Res., 109, D06115, doi:10.1029/2003JD04046, 2004.

Lee, J.-E. and Fung, I.: "Amount effect" of water isotopes and quantitative analysis of post-condensation processes, Hydrol. Proc., 22, 1-8, 2007.

Lee, J.-E., Pierrehumbert, R., Swann, A., and Lintner, B.: Sensitivity of stable isotopic values to convective parameterization schemes, Geophys. Res. Lett., 36, L23801, doi:10.1029/2009GL040880, 2009.

Liu, Q., Fu, Y., Yu, R., Sun, L., and Lu, N.: A new satellitebased census of precipitating and nonprecipitating clouds over the tropics and subtropics, Geophys. Res. Lett., 35, L07816, doi:10.1029/2008GL033208, 2008.

Masson-Delmotte, V., Jouzel, J., Landais, A., Stievnard, M., Johnsen, S. J., White, J. W. C., Werner, M., Sveinbjornsdottir, A., and Fuhrer, K.: GRIP deuterium excess reveals rapid and orbital-scale changes in Greenland moisture origin, Science, 309, 118-121, 2005.

Moyer, E. J., Irion, F. W., Yung, Y. L., and Gunson, M. R.: ATMOS stratospheric deuterated water and implications for tropospherestratosphere transport, Geophys. Res. Lett., 23, 2385-2388, 1996.

Noone, D. and Simmonds, I.: Association between $\delta^{18} \mathrm{O}$ of water and climate parameters in a simulation of atmospheric circulation 1979-1995, J. Clim., 15, 3150-3169, 2002.

Noone, D. and Simmonds, I.: Sea ice control of water isotope transport to Antarctica and implications for ice core interpretation, J. Geophys. Res., 109, D07105, doi:10.1029/2003JD004228, 2004.

Risi, C., Bony, S., and Vimeux, F.: Influence of convective processes on the isotopic composition $\left(\delta^{18} \mathrm{O}\right.$ and $\left.\delta D\right)$ of precipitation and water vapor in the tropics: 2. Physical interpretation of the amount effect, J. Geophys. Res., 113, D19306, doi:10.1029/2008JD009943, 2008a.

Risi, C., Bony, S., Vimeux, F., Descroix, L., Ibrahim, B., Lebreton, E., Mamadou, I., and Sultan, B.: What controls the isotopic composition of the African monsoon precipitation? Insights from event-based precipitation collected during the 2006 AMMA field campaign, Geophys. Res. Lett., 35, L24808, 
doi:10.1029/2008GL035920, 2008b.

Rodgers, C. D. and Connor, B. J.: Intercomparison of remote sounding instruments, J. Geophys. Res.-Atmos., 108(D3), 4116, doi:10.1029/2002JD002299, 2003.

Rossow, W. B. and Schiffer, R. A.: Advances in understanding clouds from ISCCP, B. Am. Meteorol. Soc., 80, 2261-2287, 1999.

Schmidt, G. A., Hoffmann, G., Shindell, D. T., and Hu, Y.: Modeling atmospheric stable water isotopes and the potential for constraining cloud processes and stratospheretroposphere water exchange, J. Geophys. Res., 110, D21314, doi:10.1029/2005JD005790, 2005.

Steven, B.: Atmospheric moist convection, Ann. Rev. Earth Planet. Sci., 33, 605-643, 2005.

Su, H., Jiang, J. H., Stephens, G. L., Vane, D. G., and Livesey, N. J.: Radiative effects of upper tropospheric clouds observed by Aura MLS and CloudSat, Geophys. Res. Lett., 36, L09818, doi:10.1029/2009GL037173, 2009.

Tindall, J. C., Valdes, P. J., and Sime, L. C.: Stable water isotopes in HadCM3; Isotopic signature of El-Niño-Southern Oscillation and the tropical amount effect, J. Geophys. Res., 114, D04111, doi:10.1029/2008JD010825, 2009.

Webster, C. R. and Heymsfield, A. J.: Water isotope ratios D/H, ${ }^{18} \mathrm{O} /{ }^{16} \mathrm{O},{ }^{17} \mathrm{O} /{ }^{16} \mathrm{O}$ in and out clouds map dehydration pathway, Science, 302, 1742-1745, 2003.
Worden, J., Bowman, K., Noone, D., Beer, R., Clough, S., Eldering, A., Fisher, B., Goldman, A., Gunson, M., Herman, R., Kulawik, S. S., Lampel, M., Luo, M., Osterman, G., Rinsland, C., Rodgers, C., Sander, S., Shephard, M., and Worden, H.: Tropospheric emission spectrometer observations of the tropospheric $\mathrm{HDO} / \mathrm{H}_{2} \mathrm{O}$ ratio: Estimation approach and characterization, J. Geophys. Res., 111, D16309, doi:10.1029/2005JD006606, 2006.

Worden, J., Noone, D., and Bowman, K.: Importance of rain evaporation and continental convection in the tropical water cycle, Nature, 445(7127), 528-532, doi:10.1038/nature05508, 2007.

Worden, J., Noone, D., Galewsky, J., Bailey, A., Bowman, K., Brown, D., Hurley, J., Kulawik, S., Lee, J., and Strong, M.: Estimate of bias in Aura TES HDO/ $\mathrm{H}_{2} \mathrm{O}$ profiles from comparison of TES and in situ $\mathrm{HDO} / \mathrm{H}_{2} \mathrm{O}$ measurements at the Mauna Loa Observatory, Atmos. Chem. Phys. Discuss., 10, 25355-25388, doi:10.5194/acpd-10-25355-2010, 2010.

Wright, J. S., Sobel, A. H., and Schmidt, G. A.: Influence of condensate evaporation on water vapor and its stable isotopes in a GCM, Geophys. Res. Lett., 36, L12804, doi:10.1029/2009GL038091, 2009.

Yoshimura, K., Kanamitsu, M., Noone, D., and Oki, T.: Historical isotope simulation using Reanalysis atmospheric data, J. Geophys. Res., 113, D19108, doi:10.1029/2008JD010074, 2008. 